\title{
Analysis on Training Ways of Music Memorizing in Solfeggio Teaching
}

\section{Dan Wang}

\author{
China West Normal University, Nanchong Sichuan, 637000, China
}

\begin{abstract}
Keywords: Solfeggio, Teaching process, Music memorizing, Training way.
\end{abstract}
\begin{abstract}
The premise and basis for learning musical culture is to understand and memorize music. The concrete solfeggio teaching can effectively raise students' music level and, simultaneously, train their music accomplishment. Meanwhile, the training of music memorizing ability is also the teaching objective and task required to be currently attained chiefly. This paper combines the understanding of music memorizing in practical classroom solfeggio teaching, detailedly analyzes the methods and paths to train students' pluralistic music memorizing, and provides students with effective music memorizing training methods.
\end{abstract}

\section{Introduction}

As the theoretical basis and technical course of music teaching, solfeggio is a way to teach students' music quality from solfeggio and hearing. Music memorizing, which is the central task of the whole music teaching activity, mainly includes music identification, memory consolidation and music reproduction. As very common basic music content, it is closely related to solfeggio teaching, and the two are dependent and interactive. Students need to follow the correct music memorizing law to make solfeggio exercise. This can increase students' understanding and memorizing of music to a certain extent, and enhance their learning effect and ability in the solfeggio course.

\section{General overview of solfeggio}

In the practical classroom solfeggio teaching process, the solfeggio teaching course fully involves first-level harmony, style of melody, basic common sense of music, and other theoretical content. Thus, it can be seen that solfeggio is generally considered as the most basic music course in the teaching research scope of music course. In other words, the training mode of solfeggio is mainly a way that the learning subjects sing by strengthening their hearing and reading the music score. In a specific teaching process, a certain fixed mode can be used as the main singing method and the first tone can be used as the auxiliary singing method. The major methods for hearing training mainly include hearing, singing imitation and tune discrimination etc. All such different training methods are formed through interworking of rhythms and pitches. A human being's own hearing ability determines his/her sensitivity for pitch, and only those learning individuals with highly-sensitive hearing can overcome the singing and hearing difficulty of pitch. As for the majority of learning individuals, the scientific and systematic training method is a critical means to effectively training their music memorizing ability. In addition to this, during the practical implementation of solfeggio course teaching, teachers and students need to discuss and cooperate with each other and carry out free switch and emotional experience between a teaching task and teaching content. Meanwhile, it is also a teaching process to effectively cognize the music content. Therefore, during intensifying and training the music memorizing ability, it is required to reasonably use the teaching mode to cultivate students' memorizing ability, and this is of vital practical significance for students in their music learning process.

\section{Great significance of music memorizing in solfeggio}

Music memorizing actually means students’ ability to identify, recognize and reproduce music. Generally speaking, it refers to students' special ability to strengthen recognition and memorizing of 
the music content heard, including memorizing pitch, other pitches, music beats, phonology, timbre and even the whole music content. Music memorizing is the fundamental prerequisite of carrying out other musical activities. The teaching significance of music memorizing in carrying out solfeggio teaching course is shown in the several points below: Firstly, the music memorizing ability can effectively enhance the overall solfeggio teaching effect and teaching quality. Accurate judgment over music rhythm and pitch is the necessary basic ability required by individuals to learn music. It is required to train the music-learning individuals' ear sensitivity if they long to correctly identify the overall music rhythm and reach the effect of proficiently hearing and singing the music rhythm; it is the most effective key means to enhance the music memorizing ability. Secondly, effectively improve learning individual's development of music memorizing ability and deeply arouse their internal potential. As the solfeggio teaching activity is a music teaching mode with a special property, music memorizing ability can be trained and further developed. When comprehensively concluding the training ways of music memorizing ability, music teachers can learn, systemize and conclude students' memorizing and imitating abilities, their understanding and conclusion about music pitches and other aspects with the assistance of memorizing concepts and analytical methods related to psychological course, and can detailed analyze and conclude the problems during the solfeggio teaching activity.

\section{Effective paths of solfeggio in music memorizing teaching}

\section{Stick to the basic training for hearing discrimination}

During the implementation of solfeggio teaching activities, music teachings should help students to effective master the basis and premise of learning music; namely, students should grasp how to distinguish and recognize musical symbols. Meanwhile, they should also cultivate students' good discriminating ability and clear logical thinking ability. The music score is one of the most important musical means of expression and also an indispensable symbol for people to convey information, so it is a very significant teaching link to effectively enhance students' own memorizing ability and the abilities to read and distinguish music scores so that students can learn this artistic discipline well. During the practical solfeggio teaching process, teachers need to assist students to correctly use music score in accordance with relevant standards, so that students can correctly recognize the music score and insist on the basic solfeggio training. If students fail to fully understand the music score or fail to accept systematic hearing training etc., they need to understand and memorize the music score via imitation during the practical signing process. The failure to profoundly understand the music score will affect students' music memorizing ability to a certain extent. When implementing solfeggio training for students, music teachers need to design an independent analytical system for hearing training and divide the solfeggio training into three parts, which are respectively ear-training, sightsinging and hearing. As a matter of fact, sightsinging refers to the impromptu by watching the music score. One need to be able to strictly control the pitch and music rhythm and can search more music languages and symbols in musical activities so that students can have more perceptual understanding about music rhythm. Ear training, which is a way to training the hearing ability, includes the main content of hearing and memorizing music perception, and recognizing the single tone, interval, chord and other melodic phrases in music. After students definitely understand the music concepts, teachers can properly provide individual students with hearing training. Besides, teachers need to help students to make hearing analyses based on their rich teaching experience and specialized knowledge so as to train students' music hearing ability and reaction speed. Hearing training has an important realistic function in students' music learning, because the basic analysis on hearing training can largely enhance students' abilities to distinguish and understand the music score. At present, under the modernized teaching trend, students' internal potential cannot be practically excavated due to the excessively superficial and mechanized music teaching and teacher's failure to teach students more profoundly. On the other hand, in the traditional teaching mode, teachers, the dominant roles of classrooms, give mechanized explanations and teaching to students, greatly 
restraining students' learning initiative and participation. Therefore, only the sufficient cooperation and communication between teachers and students can practically guarantee the overall teaching quality and efficiency of classroom teaching. For this reason, teachers need to guide students to establish correct learning directions and thinking, strengthen the cooperation and communication between them, actively encourage students to make independent reflections and thorough investigations, and intensify the basic training for hearing discrimination so as to guarantee the overall quality and efficiency of music teaching.

\section{Train the logical hearing ability}

As the basic course in music teaching, solfeggio has its specific regularity but is not just the pure combination and training mode between music rhythm and pitch. The solfeggio course should be a planned and purposive teaching activity, aiming to mainly improve students' music memorizing ability, and crucially training their ability to distinguish music rhythm and music score, their reaction speed and practical adaptability to changes etc. so that students can independently identify music score correctly, can increase their ability to memorize music score, and thus can better analyze and deal with all sorts of music symbols and languages caught in the music learning process. In addition to this, the music teaching process is the major course to cultivate students' aesthetic consciousness. In a music class, undoubtedly, the teacher's emotion is the most active and efficient factor to influence students' emotion; teachers can fully arouse students' sensory cognition only through rich languages, graceful movements, multimedia and other technological ways. A favorable teacher-student relation can be established during the process of emotional education and thus emotional education can be carried out effectively. Music teachers must adequately consider students' psychological characteristics and inner needs, combine the ever-changing characteristics of the times in the society and take advantage of various teaching means to actively provide aesthetic education for students so as to enhance students' imagination and creativity and, meanwhile, train their logical hearing ability. Thus, in the practical teaching process, teachers need to give students targeted and directional teaching courses for hearing training to raise their music memorizing ability. Furthermore, it is required to cultivate students' imagination. During the practical teaching process, teachers need to pay attention to training students' imaginary thinking. Since music imagination is the basis and premise for students to memorize music rhythm and music score, it is required to train students' abilities to recognize and hear the music score and rhythm. Besides, music teachers need to help students to clearly know that the music teaching process is not a static teaching phenomenon but an unpredictable dynamic teaching phenomenon. For instance, in order to well master the music score and rhythm, students are required to have certain imagination and creativity management ability, and can understand the musical art more profoundly so as to attain the goal of internalizing music. The above teaching process can effectively improve students' music-related memorizing ability, and can provide a solid motivation support for their future music learning simultaneously.

\section{Strengthen the understanding of music elements}

Ostrovsky once pointed out: a strong association between the music rhythm and music score of the whole music in memory will lead to a secure and profound understanding of the features of brand-new music. Based on the above-mentioned research significance, it means to profoundly understand and memorize music in a way in the concrete music teaching. The above passage has detailedly described the internal association between understanding and memorizing and explicitly shows the significance of understanding music during the memory development process to a certain extent. Practice has proved that the lack of adequate understanding and comprehension of music rhythm and music score will hinder the follow-up music memorizing. In the process of solfeggio teaching, the following condition may usually occur: when hearing a music melody, the majority of students are able to timely call the name but cannot memorize it. The most important influence factor is that they lack understanding and comprehension of music rhythm, beats and other music elements so that they fail to form a systematic rational understanding of the musical form. There is a necessary inherent law for the occurrence of everything and the musical art is also like this. As proved by the long-term practice, the music composition process has gradually formed its specific fixed thinking mode and 
development rule, so it is required to follow the music's own rule to comprehend and understand a piece of music works. For instance, the symmetry, correspondence, reproduction, rhythm conversion, repetition and other methods can effectively help students to memorize music. It is exactly the specific rule of music that can help students to further understand and comprehend music phenomena during learning. Therefore, profound comprehension of music elements can intensify students' ability to memorize music. In addition, as an important part of music memorizing, the movement memorizing in solfeggio teaching mainly refers to students' correct memory of the body's kinestate and movements. Under normal conditions, the music movement is a very vivid and visual means of expression and way of creation in the concrete music teaching process. During the solfeggio training, students shall be considered as the main role of classroom teaching so as to give full play to students' learning ability and initiative creativity. For instance, at the early phase of solfeggio teaching, teachers can teaching with the "Kodaly" teaching method and let one student to given hints to other students by using designated postures and positions to recognize and practice music intonation so that students have excellent music memorizing ability during the teaching of visual training.

\section{Conclusion}

To sum up, strengthening the cultivation of students' ability to memorize music is a complicated and specialized teaching activity during the concrete solfeggio teaching, and directly affects the improvement of their solfeggio level and effect. Thus, in the concrete teaching process, it is required to continuously improve students' music memorizing ability and, meanwhile, lay a solid foundation for their future music learning by training their visual thinking ability, arouse their memory about movements in teaching, providing basic training for hearing analysis and other effective paths based on students' practical conditions and their cognition degree of music.

\section{Acknowledgments}

This paper is a school-level special project of scientific research subsidization for young teachers; project number: 15D029.

\section{References}

[1] Ren Yi, Huang Hanhua, Ye Yanyan, Wei Min and Mo Lei. Promoting individuals' music hearing and memorizing level through working memory training, Music Research, 2015 (04).

[2] Luo Ling. Application of impromptu concept and method in solfeggio teaching, Journal of Nanjing University of the Arts (Music and Performance), 2012 (01).

[3] Zhang Lei. Cultivation of music memorizing ability in solfeggio, Literature and Art for The Populace, 2012 (16).

[4] Wang Xuehua. Training of technicality and cultivation of musicality in solfeggio teaching, Journal of Shenyang Normal University (Social Science), 2010 (03).

[5] Luo Li. Study on interpenetration of solfeggio and aesthetic psychology of music under the visual threshold of aesthetic education, Hundred Schools in Arts, 2011 (S2). 